\title{
Delayed diagnosis of fractured anterior arch of the atlas in a young child
}

\author{
Sergio B Sesia, ${ }^{1}$ Friederike Prüfer, ${ }^{2}$ Michael Walther, ${ }^{3}$ Daniel Studer ${ }^{4}$
}

${ }^{1}$ Department of Pediatric Surgery, University Children's Hospital (UKBB), Basel, Switzerland

${ }^{2}$ Department of Paediatric Radiology, University Children's Hospital, Basel, Switzerland ${ }^{3}$ Department of Emergency, University Children's Hospital, Basel, Switzerland

${ }^{4}$ Department of Orthopedic and Spine Surgery, University Children's Hospital, Basel, Switzerland

\section{Correspondence to} Dr Sergio Sesia, sergio.sesia@ukbb.ch

Accepted 23 December 2016

CrossMark

To cite: Sesia $S B$, Prüfer $F$, Walther $\mathrm{M}$, et al. BMJ Case Rep Published online: [please include Day Month Year] doi:10.1136/bcr-2016214472

\section{SUMMARY}

A 2-year-old girl fell off a bunk bed onto a parquet floor. She immediately reported neck pain and presented with muscle spasm and limited motion of the cervical spine (C-spine). Plain X-rays of the C-spine showed no osseous lesion. Owing to persisting pain and limited motion in the neck, MRI of the C-spine was obtained which revealed intact ligaments and cervical spinal cord, as well as soft tissue swelling in front of the anterior arch of the atlas. Subsequent $\mathrm{CT}$ of the $\mathrm{C}$-spine confirmed a complete, undisplaced fracture of the anterior arch of the atlas (Gehweiler type I fracture). A Minerva cast was applied for 2 months, followed by a soft cervical collar. Persistent neck pain and limited range of motion of the neck after a fall may be indicative of atlas fracture that should be ruled out by $\mathrm{CT}$.

\section{BACKGROUND}

Although cerebral concussion is a common reason for referring a child to a paediatric emergency department, concomitant severe injuries of the $\mathrm{C}$-spine are rare. ${ }^{1}$ Spinal cord injuries and vertebral column fractures in early childhood are reported to range between $1 \%$ and $10 \%$ of all spinal injury admissions. ${ }^{2}$ Toddlers represent a distinct group of children at particular risk for high cervical and craniocervical injury. ${ }^{3}$ Toddlers have a proportionally bigger head compared with adults. Therefore, even minor trauma may cause a fracture of the $\mathrm{C}$-spine. Before the age of 8 years, C-spine injuries occur mainly in the upper $\mathrm{C}$-spine above $\mathrm{C} 4$ involving most often the $\mathrm{C} 1 / \mathrm{C} 2$ complex, which increases the risk of fatality. Children older than 8 years typically sustain more injuries below $\mathrm{C} 4$ with a lower risk of fatality. ${ }^{5}$ Up to $20 \%$ of traumatic spine injuries in children present as a traumatic myelopathy known as spinal cord injury without radiographic abnormality. ${ }^{6}$ Commonly performed plain X-rays of the C-spine may fail to detect such fractures. ${ }^{7}$ The dilemma is when to proceed to further investigations.

We report on a 2-year-old girl with isolated, undisplaced fracture of the anterior arch of the atlas, also known as the hypochordal bow (Gehweiler type I fracture). ${ }^{8}$

\section{CASE PRESENTATION}

A 2-year-old girl presented to our hospital with neck pain after falling off a bunk bed onto a parquet floor, from a height of $1.7 \mathrm{~m}$. Non-accidental injury was ruled out. The child reported persisting neck pain. Besides reduced range of neck motion and cervical muscle guarding, the physical findings were unremarkable (no midline tenderness, no palpable 'step-off', no swelling at the back of the neck). Neurological examination was unremarkable. Anteroposterior and lateral X-rays of the $\mathrm{C}$-spine showed no osseous lesion and no prevertebral soft tissue swelling (figure 1). Owing to cervical muscle spasm and lack of cooperation by the patient, it was not possible to obtain an open-mouth odontoid view. The suspected injury to the head and neck after the fall from a height $>1.0 \mathrm{~m}$ necessitated the placement of a soft cervical collar and hospitalisation for observation. Two days after admission, the patient still reported persisting neck pain and the inability to move the neck. Therefore, an MRI and CT scan of the C-spine were performed under general anaesthesia. The MRI showed soft tissue oedema in front of the anterior arch of the atlas but no visible signs of atlas fracture (figure 2). The CT scan revealed an undisplaced fracture of the anterior arch of the atlas (Gehweiler type I fracture; figure 3). ${ }^{8}$ A Minerva
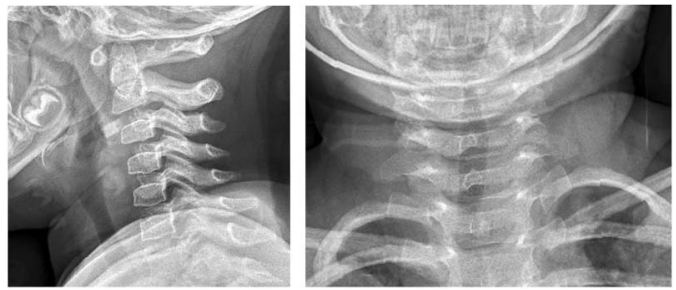

Figure 1 Anteroposterior and lateral plain X-rays of the cervical spine.

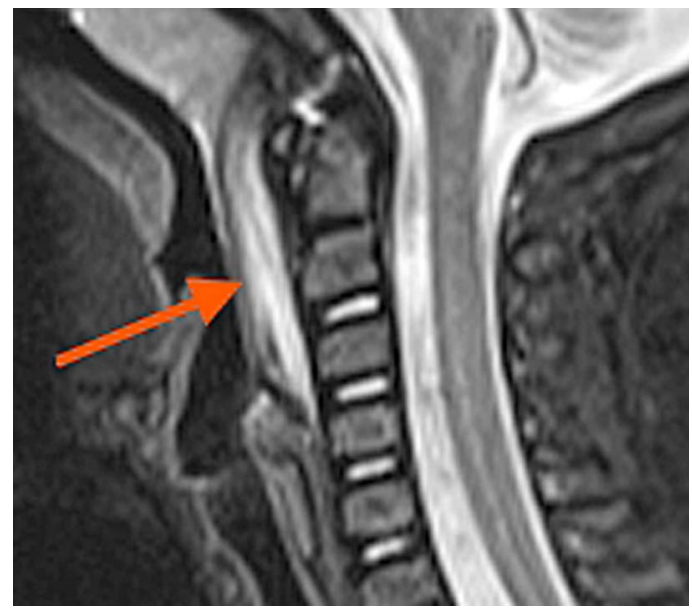

Figure 2 T2-weighted sagittal MRI of the C-spine showing an oedema in the prevertebral soft tissues (red arrow). 

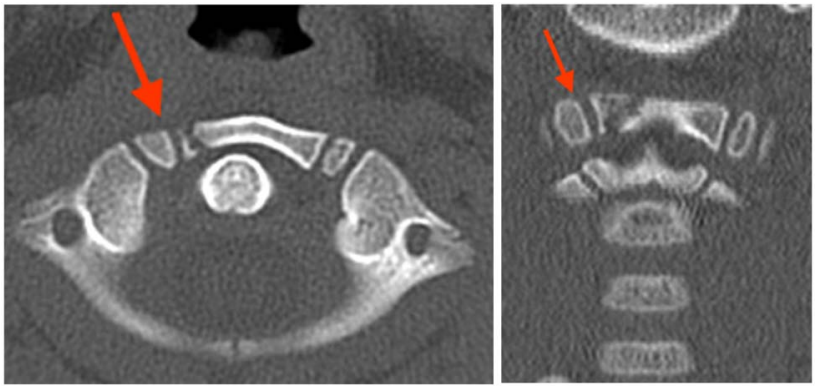

Figure 3 Sagittal CT of the C-spine showing an undisplaced fracture of the right anterior arch of the atlas (red arrow).

cast was applied immediately after imaging. The neck was immobilised for 2 months (figure 4), followed by soft cervical collar application for an additional 3 weeks. The child remained neurologically asymptomatic and regained full range of motion of the neck.

\section{INVESTIGATIONS}

Owing to neck pain and limited range of motion, plain X-ray of the C-spine was performed, but no signs of fractures were apparent (figure 1). MRI of the C-spine demonstrated prevertebral soft tissue oedema (figure 2). CT scan of the C-spine revealed a complete but undisplaced fracture of the anterior arch of the atlas (figure 3 ).

\section{DIFFERENTIAL DIAGNOSIS}

Interpretation of paediatric C-spine radiographs is difficult. There are various normal variants, including pseudosubluxation between $\mathrm{C} 2 / \mathrm{C} 3$ and $\mathrm{C} 3 / \mathrm{C} 4$, absence of $\mathrm{C}$-spine lordosis, and incomplete ossification. ${ }^{6}$ The atlas has three primary ossification centres, ${ }^{9}$ that is, one anterior centre for the formation of the anterior tubercle and two lateral centres for the formation of the posterior arch. At birth, the posterior arches are almost fused. Between 5 and 9 years of age, the anterior centre fuses. ${ }^{10}$ Incomplete fusion may persist and may explain congenital malformations of the arches of C1. However, congenital malformations of the atlas are very rare, and anterior arch defects are even less common. ${ }^{11}$ Anomalies may appear as clefts between the arches in the posterior midline or in the form of the complete absence of one or both posterior arches. Furthermore,

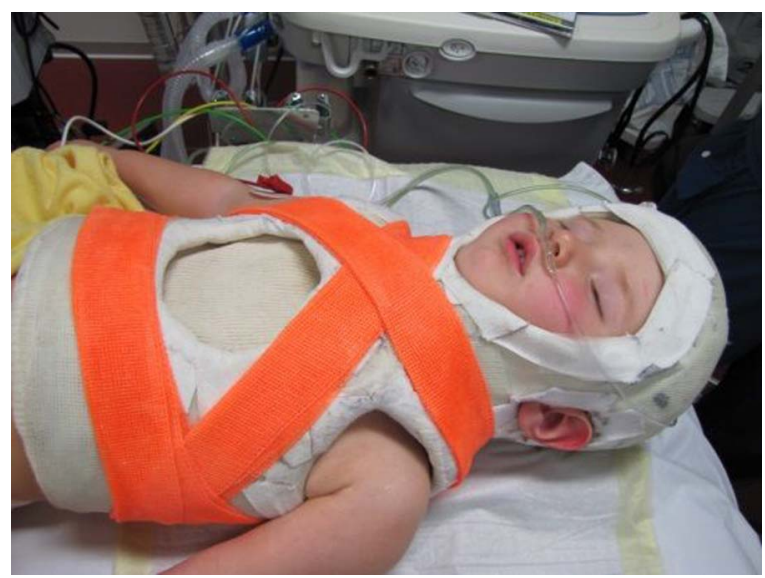

Figure 4 Minerva cast (3M Scotchcast, 3M (Suisse) S.à.r.l., Rüschlikon, Switzerland). variability of maturation of synchondrosis may cause pitfalls in the interpretation of the growing C-spine. ${ }^{6}$

\section{TREATMENT}

The fracture was immobilised using a Minerva cast for 2 months followed by a soft cervical collar for an additional 3 weeks.

\section{OUTCOME AND FOLLOW-UP}

The child remained neurologically asymptomatic and regained full range of motion of the neck 2 months after the injury. Interestingly, even after 2 months of Minerva cast immobilisation, there was no adequate fracture consolidation on follow-up CT scans.

\section{DISCUSSION}

Five groups of atlas fractures have been described: isolated fractures of the anterior arch of the atlas, isolated fractures of the posterior arch, combined fractures of the anterior and posterior arch (Jefferson fractures), isolated fractures of the lateral mass, and fractures of the transverse process. ${ }^{12}$ A similar fracture was reported by Bayar $e t a l^{3}$ in a girl 2.5 years of age. The anterior arch fracture gap of the atlas measured $2 \mathrm{~mm}$, and treatment consisted of immobilisation in a firm cervical collar. Like in our patient, a follow-up CT scan obtained after 2 months showed delayed union of the fracture with sclerosis formation on both edges of the fracture gap. The cervical orthosis was removed after 3 months after repeat CT scan had demonstrated fusion of the fracture. ${ }^{3}$

Compared with adults, children rarely injure their C-spine and even less often the atlas. ${ }^{13-15}$ Limited exposure to highenergy traumata may explain the very low incidence of atlas fractures in children. Different factors influence the flexibility of the growing spine, such as incompletely ossified and cartilaginous bones, laxity of intervertebral ligaments, underdeveloped neck musculature, an increased cranium to body weight ratio, and a higher fulcrum for cervical motion at C2-C3. ${ }^{15} 16$ Thus, the greater susceptibility to trauma in children reflects a different trauma mechanism of adults and children. In adults, $\mathrm{C}$-spine, and in particular atlas fractures, mainly occur in motor vehicle incidents with high deceleration forces while in children, the atlas may fracture even with minor forces as presented in this child who fell from a height of $1.7 \mathrm{~m} .{ }^{17}$ The main causes of paediatric trauma are falls in children aged 0-9 years and motor vehicle collisions in adolescents aged $10-18$ years. ${ }^{18}$

Effective C-spine immobilisation while evaluating a C-spine injury is mandatory. To prevent aggravation of an existing spinal cord injury, any child with suspected C-spine injury must be immobilised with a cervical collar or spine board until a spinal cord injury is ruled out clinically or radiographically. ${ }^{19}$ The proportionally larger head of the young child will cause increased flexion of the C-spine when placed on a standard backboard. Therefore, the child has to be transported on a fenestrated board with the $\mathrm{C}$-spine in neutral alignment. The $\mathrm{C}$-spine has to be immobilised manually during airway management. For clinical evaluation, the cervical collar may be removed as long as in-line immobilisation is ensured. If the patient has symptoms suggestive of a C-spine fracture or spinal cord injury, the collar must be applied again, followed by radiological investigation.

Diagnosing an isolated atlas fracture may be challenging. Clinical signs are frequently unspecific, such as neck pain, muscle spasm and limited range of motion. ${ }^{15} 20$ Retropharyngeal swelling may impair swallowing. However, neurological deficits are rare and are mostly accompanied by concomitant spinal injuries. ${ }^{21}$ In our case, the main symptom 
was persisting neck pain. This symptom made us aware of a possible fracture of the upper C-spine. Richards ${ }^{20}$ mentioned in their publication on fractures of the atlas and axis in children that all three children with stable, undisplaced fractures presented initially at a general hospital, and the diagnosis was missed. This is in consistence with the delay in establishing the diagnosis in our patient.

As reported by Slack and Clancy, ${ }^{6}$ a gold standard that identifies all $\mathrm{C}$-spine injuries in children does not exist. To avoid unnecessary and expensive X-ray investigations, two clinical decision principles have been developed to assist in deciding which patients warrant $\mathrm{C}$-spine imaging. These guidelines are based on the National Emergency X-radiography Utilization Study (NEXUS) and the Canadian Cervical Spine Rule (CCR). NEXUS involves only five criteria (no midline cervical tenderness; no focal neurological deficit; normal alertness; no intoxication; no painful, distracting injury) and can be applied to adults and children. The CCR does not apply to all patient populations (eg, patients older than 64 years), is more complex because it requires the patient to have a Glasgow Coma Scale of 15 , focuses on the mechanism of incident (rear-end collision), and includes the assessment of the patients' ability to actively rotate their neck, both to the left and to the right, at a $45^{\circ}$ angle without pain. Comparative studies have shown that physicians are not comfortable with testing the range of motion, even if CCR has a higher sensitivity and specificity than NEXUS. ${ }^{22}$

The radiographic findings play an important role in detecting fractures of the atlas. Initial imaging is based on X-rays with additional open-mouth views to visualise the dens. However, obtaining an open-mouth view in young children with cervical stiffness may be very challenging or even impossible. Although it is reasonable to keep radiation exposure as low as possible, further investigations should always be considered in the case of unremarkable X-rays with persisting neck pain and limited range of neck motion. ${ }^{23}$ Our patient did not demonstrate any prevertebral soft tissue swelling, an indirect sign of a fracture of the C-spine, on plain X-ray images. ${ }^{24}$ Therefore, we decided to perform an MRI of the C-spine in accordance with the suggestion of Judd $e t \mathrm{al}^{25}$ to further assess the integrity of the atlantal ligament. Although this did not confirm the spine fracture, MRI verified the integrity of ligaments, ruled out congenital malformations and helped to detect prevertebral haematoma. However, the fracture of the right anterior arch of the atlas could not be detected until we obtained a CT scan of the $\mathrm{C}$-spine. These observations are in accordance with results of other studies reporting that a CT scan is more sensitive than $\mathrm{X}$-ray or MRI to detect fractures of the upper $\mathrm{C}$-spine in children. ${ }^{2126}$

Young children do not necessarily need general anaesthesia to undergo CT scans or MRI. Often, procedural sedation is all that is needed. ${ }^{27}$ To provide safety and comfort for the patient and ensure high image quality, both scans (MRI and CT) were realised under general anaesthesia in the present case. However, both scans and the subsequent placement of Minerva cast were done during the same anaesthesia.

Fractures of the atlas are caused by vertical compressive forces and affect the weakest points of the atlas. ${ }^{28}$ If the compressive forces on the lateral masses of the atlas are strong enough, separation of the lateral masses together with an avulsion of the transverse atlantal ligaments may occur (Jefferson fracture), thus resulting in atlanto-occipital instability. ${ }^{29}$ The rule of Spence defines that when the lateral masses are displaced from each other by more than $6.9 \mathrm{~mm}$ after an atlas fracture, in an adult, the transverse ligament is probably torn. ${ }^{30}$ However, no such measurements have been established for children. Keene and colleagues suggested that by CT studies of the upper C-spine, fractures and displacement of the atlas relative to the odontoid process can be readily shown and correctly assessed. ${ }^{31}$ Most authors apply the rule of Spence in children to discern unstable from stable atlas fractures. ${ }^{30}$ However, it must be noted that these measurements were proposed to rule out atlantoaxial instabilities in adults. ${ }^{30}$ The majority of authors treat atlas fractures in children non-operatively and apply rigid neck orthoses for 8-12 weeks. ${ }^{3} 202125$ To rule out residual instability or malalignment of the upper C-spine, some authors obtain delayed flexion-extension radiographs after removal of the cervical orthosis at the end of the immobilisation period. ${ }^{25}$

Treatment strategies for atlas fractures in children are discussed controversially. ${ }^{31}$ We agree with Kazanci $e t a l^{21}$ that management of stable and unstable fractures of the atlas Gehweiler type I in toddlers depends on whether they occur in combination with or without other C-spine injuries or alone. $^{21} 32$ Isolated anterior arch fractures of $\mathrm{C} 1$ can be managed with a rigid cervical brace, a Minerva plaster of Paris vest, a prefabricated sterno-occipital-mandibular orthosis, or a halo-thoracic brace for 8-12 weeks. $^{3}{ }^{21}$ In a series of 29 adult patients with isolated atlas fractures, Hadley ${ }^{32}$ observed no non-union, instability on dynamic flexion-extension radiographs, or neurological deficit after a median follow-up of 40 months. Kazanci et $a l^{21}$ published a case report of a 6 -year-old boy who suffered an isolated fracture of the anterior part of the atlas which was not treated effectively with a cervical collar for the initial 10 weeks and developed radiological signs of delayed union at the fracture site. After further effective cervical immobilisation, they noted consolidation of the fracture. ${ }^{21}$ Judd et $a l^{25}$ recommended treatment of paediatric atlas fractures using rigid bracing such as a Minerva jacket or rigid Malibu cervical collar orthosis. All cases of isolated C1 fractures reported in the literature, except the patient originally described by Jefferson, ${ }^{28}$ survived and recovered with full function. If there is no disruption of the ligaments or displacement of fragments, fractures of the atlas are considered stable and can be treated conservatively. ${ }^{25}$ External hard or soft collars, halo braces, or casts are recommended treatment options. Although such stable fractures are commonly treated using hard cervical orthoses, we applied a Minerva cast for 8 weeks according to our usual policy because this was a particularly active child.

Even after 2 months of Minerva cast immobilisation, there was no adequate fracture consolidation on follow-up CT scans. The fracture gap of the lateral part of the anterior arch of the atlas showed neither sclerosis nor signs of adequate fusion in the follow-up CT scan. We decided against further CT scans due to the proximity of the fracture line to the thyroid gland and the evidence provided by Kazanci et al that even 10 weeks after the injury, there may be signs of delayed osseous union at the fracture site on CT scans. ${ }^{21}$ Keeping in mind the study by Hadley $^{32}$ who demonstrated that even in adults, no non-union in atlas fractures occurred after a median follow-up of 40 months, we considered it appropriate to do no further CT scans in this infant who was free of symptoms, such as functional deficits and other symptoms. In accordance with the suggestions of Muthu $e t a l^{33}$ who stated that the congenital nature of a defect of the atlas can be distinguished from an acute fracture by its midline localisation and the presence of a smooth, sclerotic margin, we were able to exclude a congenital deformity of the atlas. 
Surgical management may be considered for unstable fractures with disruption of the transverse ligament. ${ }^{25} 34$

Generally, atlas fractures have a favourable outcome. In up to $70 \%$ of cases, atlas fractures are associated with another fracture of the C-spine. ${ }^{21}$ Prognosis depends on the severity of the concomitant spinal cord injury. ${ }^{35}$ Richards ${ }^{20}$ reported on three children who had sustained a stable fracture of the atlas and axis with a neurological deficit. All children were treated by application of a plaster of Paris Minerva jacket and their neurological deficit improved or healed within a period of 3 months. ${ }^{20}$ In Richards ${ }^{20}$ series of stable fractures of the atlas and axis in children he used no other treatment than a soft cervical collar for 6 weeks, and although a firm collar was substituted, a recovery was beginning to be seen by 8 weeks. Richards postulated that stable, undisplaced fractures of the atlas and axis represent a benign injury. Richards concludes that although children tolerate firm braces and Minerva jackets well it would be less comfortable for them to wear a firm collar. He considered the firm collar as the treatment of choice for this rare injury in young children. $^{20}$

Neurological recovery after cervical spinal cord injury in children is usually better than in adults. However, children carry a higher risk to develop scoliosis, especially if the injury occurred before the growth spurt. ${ }^{36}$ The main factors affecting the prognosis of C-spine injuries with neurological deficits are the primary neurological status, and presence of a spinal cord oedema in the MRIs. ${ }^{37}$

We describe the case of an undisplaced fracture of the anterior arch of the atlas, which was visualised with CT scan imaging. We confirmed the integrity of the transverse atlantal ligament and the lack of significant injury to the surrounding soft tissues and ligaments of the upper C-spine by MRIs. Therefore, we considered the fracture to represent a stable Gehweiler type I anterior arch fracture of the atlas and opted for non-operative treatment in accordance with the recommendations provided in the literature. $^{8} 1025$

\section{Learning points}

- Atlas fractures in children are rare.

- Consider atlas fracture in the presence of persisting pain and limited range of motion of the neck after a fall.

- CT scan is the most accurate diagnostic modality to diagnose atlas fractures in young children.

- Undisplaced atlas fractures without disruption of spinal ligaments in children can be managed conservatively with external immobilisation.

- Consider sectional imaging in any suspicion of clinical or radiographic C-spine injury. Keep C-spine immobilisation as long as an instable injury is suspected.

Acknowledgements The authors would like to express their sincere gratitude to Professor Johannes Mayr for his immense knowledge, and comments that greatly improved the manuscript.

Contributors SS, FP, MW and DS conceived and designed the protocol. All authors were involved in amending the protocol. SS wrote the first draft of the manuscript, and all authors contributed to subsequent and final versions.

Competing interests None declared.

Patient consent Obtained.

Provenance and peer review Not commissioned; externally peer reviewed.

\section{REFERENCES}

1 Brown RL, Brunn MA, Garcia VF. Cervical spine injuries in children: a review of 103 patients treated consecutively at a level 1 paediatric trauma center. J Pediatr Surg 2001;36:1107-14.

2 Hamilton MG, Myles ST. Pediatric spinal injury: review of 61 deaths. J Neurosurg 1992:77:705-8

3 Bayar MA, Erdem Y, Ozturk K, et al. Isolated anterior arch fracture of the atlas: child case report. Spine 2002;27:E47-9.

4 Ghatan S, Newell DW, Grady MS, et al. Severe posttraumatic craniocervical instability in the very young patient. Report of three cases. J Neurosurg 2004;101(Suppl 1):102-7.

5 Piatt JhJr, Grissom LE. Developmental anatomy of the atlas and axis in childhood by computed tomography. J Neurosurg Pediatr 2011;8:235-43.

6 Slack SE, Clancy MJ. Clearing the cervical spine of paediatric trauma patients. Emerg Med J 2004;21:189-93.

7 Mower WR, Hoffman JR, Pollack CV Jr., et al. Use of plain radiography to screen for cervical spine injuries. Ann Emerg Med 2001;38:1-7.

8 Gehweiler JA, Osborne RH, Becker RF. The radiology of vertebral trauma. Philadelphia: Saunders, 1983.

9 Garg A, Gaikwad SB, Gupta V, et al. Bipartite atlas with os odontoideum: case report. Spine 2004;29:E35-8.

10 Sharma A, Gaikwad SB, Deol PS, et al. Partial aplasia of the posterior arch of the atlas with an isolated posterior arch remnant: findings in three cases. AJNR Am I Neuroradiol 2000;21:1167-71.

11 Senoglu M, Safavi-Abbasi S, Theodore N, et al. The frequency and clinical significance of congenital defects of the posterior and anterior arch of the atlas. J Neurosurg Spine 2007;4:399-402.

12 Schären S, Jeanneret B. Atlas fractures. Orthopäde 1999;28:385-93.

13 Bohn D, Armstrong D, Becker L, et al. Cervical spine injuries in children. J Trauma 1990;30:463-9.

14 Sherk HH, Nicholson JT. Fractures of the atlas. J Bone Joint Surg Am 1970;52:1017-24.

15 Platzer $P$, Jaindl $M$, Thalhammer $G$, et al. Cervical spine injuries in pediatric patients. J Trauma 2007;62:389-96; discussion 394-6.

16 Knox JB, Schneider JE, Cage JM, et al. Spine trauma in very young children: a retrospective study of 206 patients presenting to a level 1 pediatric trauma center. J Pediatr Orthop 2014;34:698-702.

17 AuYong N, Piatt J Jr. Jefferson fractures of the immature spine. Report of 3 cases. J Neurosurg Pediatr 2009;3:15-19.

18 Tracy ET, Englum BR, Barbas AS, et al. Pediatric injury patterns by year of age. J Pediatr Surg 2013;48:1384-8.

19 Skellett S, Tibby SM, Durward A, et al. Lesson of the week: immobilisation of the cervical spine in children. BMJ 2002;324:591.

20 Richards PG. Stable fractures of the atlas and axis in children. J Neurol Neurosurg Psychiatr 1984;47:781-3.

21 Kazanci $B$, Kahveci R, Ekici MA, et al. Isolated fracture of anterior arch of atlas in a child: case report and review of the literature. Injury 2013;44:1956-8.

22 Eyre A. Overview and comparison of NEXUS and Canadian c-spine rules. Am J Clin Med 2006:3:12-15.

23 Ellis GL. Imaging of the atlas (C1) and axis (C2). Emerg Med Clin North Am 1991;9:719-32.

24 Baghdassarian A, Piatt JHJr, Giordano K. Fracture of the anterior arch of atlas after minor trauma of the immature spine postlaminectomy. Pediatr Emer Care 2014;30:340-2.

25 Judd DB, Liem LK, Petermann G. Pediatric atlas fracture: a case of fracture through a synchondrosis and review of the literature. Neurosurgery 2000;46:991-4.

26 Keene GC, Hone MR, Sage MR. Atlas fracture: demonstration using computerized tomography. A case report. J Bone Joint Surg Am 1978;60:1106-7.

27 Grunwell JR, Marupudi NK, Gupta RV, et al. Outcomes following implementation of a paediatric procedural sedation guide for referral to general anesthesia for magnetic resonance imaging studies. Paediatr Anaesth 2016;26:628-36.

28 Jefferson $G$. Fractures of the Atlas vertebra. Report of four cases and a review of those previously recorded. Br J Surg 1920;7:407-11.

29 Kakarla UK, Chang SW, Theodore N, et al. Atlas fractures. Neurosurgery 2010;66:60-7.

30 Spence KFJr, Decker S, Sell KW. Bursting atlantal fracture associated with rupture of the transverse ligament. J Bone Joint Surg Am 1970;52:543-9.

31 Vermess D, Rojas CA, Shaheen F, et al. Normal pediatric prevertebral soft-tissue thickness on MDCT. AJR Am J Roentgenol 2012;199:W130-3.

32 Hadley MN. Isolated fractures of the atlas in adults. Neurosurgery 2002;50:120-4.

33 Muthu SK, Cox S, Gunawardena WJ, et al. Anteroposterior spondyloschisis of the atlas. Two case reports and literature review. Emerg Radiol 2007;13:337-40.

34 Ryken TC, Aarabi B, Dhall SS, et al. Management of isolated fractures of the atlas in adults. Neurosurgery 2013;72(Suppl 2):127-31.

35 Turk G, Kabakus IM, Akpinar E. Fracture of the atlas through a synchondrosis of anterior arch. Case Rep Radiol 2013;2013:934135.

36 Parent S, Mac-Thiong JM, Roy-Beaudry M, et al. Spinal cord injury in the pediatric population. A systematic review of the literature. J Neurotrauma 2011;28:1515-24.

37 Narasinga Rao KVL, Vijaya Saradhi M, Purohit AK. Factors affecting long-term outcome in acute cervical cord injury. Indian J Neurotrauma 2010;7:149-56. 
Copyright 2017 BMJ Publishing Group. All rights reserved. For permission to reuse any of this content visit http://group.bmj.com/group/rights-licensing/permissions.

BMJ Case Report Fellows may re-use this article for personal use and teaching without any further permission.

Become a Fellow of BMJ Case Reports today and you can:

- Submit as many cases as you like

- Enjoy fast sympathetic peer review and rapid publication of accepted articles

- Access all the published articles

- Re-use any of the published material for personal use and teaching without further permission

For information on Institutional Fellowships contact consortiasales@bmjgroup.com

Visit casereports.bmj.com for more articles like this and to become a Fellow 